\title{
A High Frequency Mutation Starts Sexual Reproduction in Volvox carteri
}

\author{
Bernd Weisshaar, Rainer Gilles, Regina Moka, and Lothar Jaenicke \\ Institut für Biochemie, Universität zu Köln, An der Bottmühle 2, D-5000 Köln 1, \\ Bundesrepublik Deutschland
}

Z. Naturforsch. 39c, 1159-1162 (1984); received July 6, 1984

Cell Lineages, Mutation, Sexual Induction, Volvox carteri

Pheromone-initiated sexual reproduction of Volvox carteri f. nagariensis is started by a "spontaneous" generation of sexual male spheroids at a rate of $10^{-4}$. As previously suggested, these males are mutants $\left(\operatorname{sex}^{c}\right)$ which become independent of pheromone-controlled sexinduction. Unequivocal evidence for a mutative event now comes from the observation that the $\operatorname{sex}^{\mathrm{c}}$ trait is transmitted through cell lineages during embryogenesis, thus confirming earlier morphological analysis. Mutation seems to be restricted to cell division. The high frequency of mutation points to a special enhancing mechanism for which the possibility of a genome rearrangement is discussed.

The multicellular green alga Volvox carteri f. nagariensis multiplies asexually by strictly ordered cleavages of its up to 16 gonidia [1] (Fig. 1). On sexual reproduction the gonidia of male and female strains differentiate to form spheroids with sperm packets and eggs, respectively. This is accomplished by a species-specific high-molecular pheromone released into the medium by disintegrating spermpackets [2]. Since the pheromone is only produced by sexual males, the obvious question is, how the first male becomes sexual. Occasionally, in asexual male cultures, sexual male spheroids appear which, on maturation, release sufficient inducer to turn sexual the spheroids of the next generation. R. C. Starr supposed these "spontaneous" males to be mutants in which a gene controlling the sexual development is affected [3, 4]. The frequency of their occurrence is $1.8 \times 10^{-4}$ [5], approx. two orders of magnitude higher than that given for other mutations in Volvox [6]. It was therefore assumed that - in addition to mutations - entry into the sexual pathway is due to response either to an unknown environmental signal [5] or to accumulating inducer produced in trace amounts by asexual male cultures [7]. The usual test for a mutation, i.e. to check whether the trait can be established in a clonal culture, is not practicable in this case, since sexual males disintegrate completely, and an intercross with female strains and sperms from one male only is technically very difficult. Thus, the question which mechanism is responsible for "spontaneous" males is still open. In this communication we present

Reprint requests to Prof. Dr. L. Jaenicke.

0341-0382/84/1100-1159 \$01.30/0 evidence for an inducer-independent appearance of the first males in an asexual culture. Our data also indicate that the basic event is on the DNA level and occurs at the early stages of embryogenesis.

\section{Materials and Methods \\ Culture conditions}

The female strain HK-10 and the male strain 69-1 b of Volvox carteri f. nagariensis Iyengar were obtained from R. C. Starr (Culture Collection of Algae, University of Texas). The algae were grown axenically in Volvox medium [8] at $28^{\circ} \mathrm{C}$ in a light/ dark rhythm of 16:8 h (10000 lux).

\section{Screening for $\operatorname{sex}^{\mathrm{c}}$ mutants}

Asexual cultures were started with one young spheroid in phase I (see Fig. 1) in $10 \mathrm{ml}$ Volvox medium. After 5 days algae containing the $3 \mathrm{rd}$ generation offspring $(3300 \pm 200)$ were scored under a dissecting microscope. By screening in phase IV, i.e. before hatching of the young individuals, we were able to deduce in which gonidium the mutation occurred. As an additional method, the inducer found in the medium of male cultures with $\operatorname{sex}^{\mathrm{c}}$ mutants was measured: $1 \mathrm{ml}$ medium of a six day test tube culture was inoculated with $3 \mathrm{HK}-10$ spheroids (phase IV) for bioassay [8]. Both methods gave corresponding results.

Micrographs were taken with a Leitz Dialux 20 microscope.

\section{Results and Discussion}

The rate of spontaneous induced males and females was estimated by scoring a large number of test tube
This work has been digitalized and published in 2013 by Verlag Zeitschrift für Naturforschung in cooperation with the Max Planck Society for the Advancement of Science under a Creative Commons Attribution-NoDerivs 3.0 Germany License. 


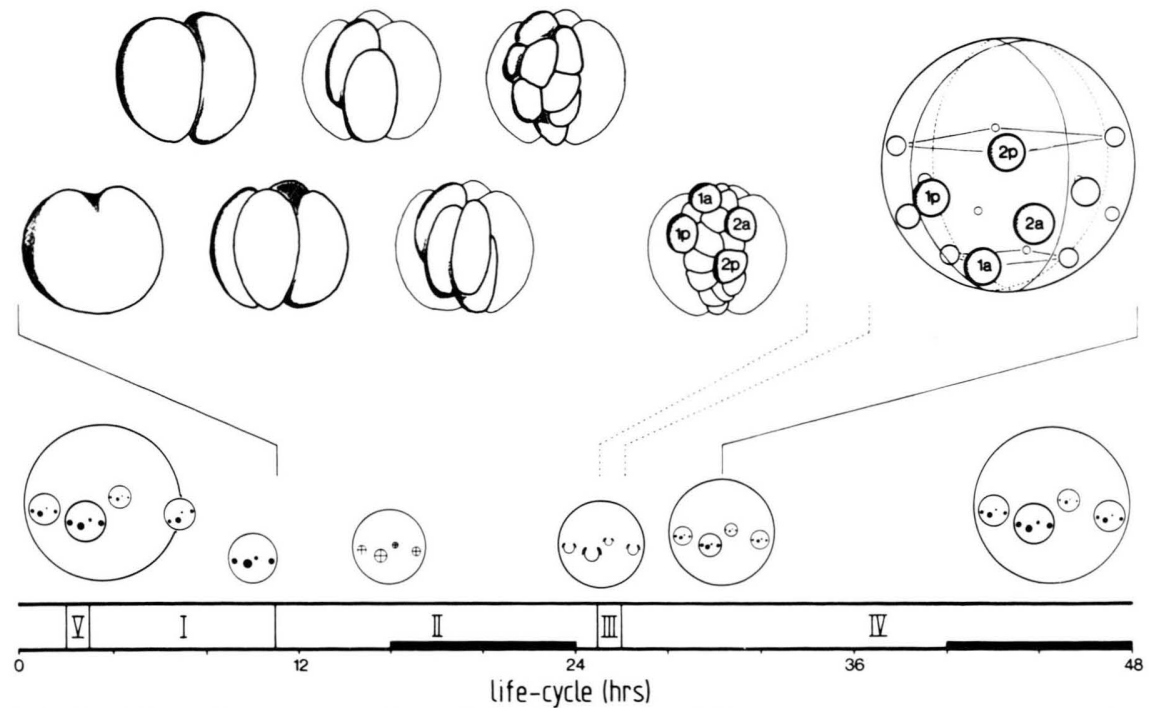

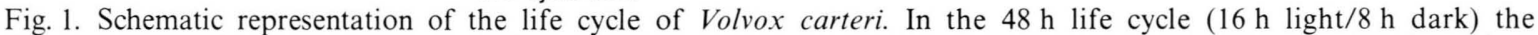
developmental phases (I to V) are indicated [12]. I: growth of young spheroids; II: cell cleavages; III: inversion; IV: growth of adult spheroids; V: release of progeny. - In the lower part, spheroids are shown with only one tier of 4 gonidia rather than with the total of 16. In the upper part, asexual development of one gonidium is depicted up to the 64-cell stage. All the cell stages are drawn with the anterior pole (phialopore) on top. After the 8-celled embryo, all cleavages are shown in one quarter only. According to nomenclature of [13], the 8-celled embryo consists of an anterior (cells $1 / 3$ ) and a posterior tier (cells $2 / 4$ ). Since the next cleavage is also oblique, 4 extensively overlapping tiers (cells 1, 2, 3, and 4) arise. The following equatorial cleavage sets apart anterior and posterior derivatives. Cells $1 a, 1 p, 2 a$, and $2 p$ of the 32-celled embryo are gonidial stem cells. They cleave unequally (6th division) to large gonidial initials, labelled in the figure according to their stem cells, and small somatic precursor cells. The gonidial initials cleave unequally additional three times, while all other cells cleave until the total cell number of 2000 is reached. Then the embryo turns inside out (inversion). During inversion, the anterior pole of the embryo becomes the posterior pole of the young spheroid, also represented here. Note: Positioning of the gonidia in the young spheroid is the inverted one of the 64-cell stage. On sexual reproduction, unequal cleavage is delayed one stage ( 7 th division) for the female strain; for the male strain, the last cleavage ( 7 th or 8 th division) is unequal for all cells.

cultures as described in Materials and Methods. We found a frequency of $1.1 \times 10^{-4}$ for male as well as for female strains. For the latter we could prove, in accordance with Starr [4] that all isolates are mutants and produce eggs in each generation without inducer present*. A mutation rate of $>1: 10000$ is extremely high, and a special enhancing mechanism will be required. In contrast to [5] we obtained no differences between the sexes. Thus, it seems to be very likely that spontaneous males originate from the same mutational mechanism as the female $s e x^{\mathrm{c}}$ mutants.

Surprisingly, cultures of both sexes showed parental spheroids bearing not only one, but two, four and even eight sexual daughter spheroids (Table I and Fig. 2). These individuals cannot originate from independent events, since the statistical probability would be $\leqq 10^{-8}$, and the distribution of mutated daughters within the parent is not random at all.

* In cultures of these spontaneous females revertants to wildtype are found at high frequency.
Spheroids with 16 gonidia contain 4 quadrangular tiers of 4 gonidia each [9] (Fig. 1). The same holds for the positioning of the young spheroids after cleavage of the gonidia. Four gonidia lying in one quarter of the spheroid arise from one blastomere of the 4-celled embryo; two each of the gonidia have a common precursor cell at the 16-cell stage. Without exception, multiple sexual individuals are in positions which belong to one cell lineage (Fig. 1).

The existence and position of derivatives of spontaneous induced daughter spheroids are compelling arguments to postulate that the initial event occurs during embryogenesis of the preceding generation when the 16 gonidia, now forming the partially induced offspring, arise from a single gonidium. This explains why more than one sexual individual is formed by a single event. If during the 2-cell stage one blastomere is mutated, half of the resulting embryo ( 8 gonidia) will form sexual offspring in the next generation. If the same happens at the 4-cell stage, four, and at the 8- or 16-cell stage, two spon- 
Table I. Data were obtained by screening 410000 male and 220000 female individuals, respectively. The mutation rate is $1.1 \times 10^{-4}$ for both sexes. The ratio of multiple to single spontaneous induced offspring is $16: 52$ or $1: 3.25$. Position of sexual daughter spheroids is given as indicated in Fig. 1.

\begin{tabular}{|c|c|c|c|c|}
\hline Number of sexuals per spheroid & Position of sexuals & $\begin{array}{l}\text { Males } \\
69-1 \text { b }\end{array}$ & $\begin{array}{l}\text { Females } \\
\text { HK-10 }\end{array}$ & Total \\
\hline $\begin{array}{l}8 \\
4 \\
2\end{array}$ & $\begin{array}{l}2 \mathrm{x}(1 \mathrm{a}, 1 \mathrm{p}, 2 \mathrm{a}, 2 \mathrm{p})^{\mathrm{a}} \\
1 \mathrm{a}, 1 \mathrm{p}, 2 \mathrm{a}, 2 \mathrm{p}^{\mathrm{b}} \\
1 \mathrm{a}, 1 \mathrm{p} \mathrm{b}^{\mathrm{b}} \\
2 \mathrm{a}, 2 \mathrm{p}^{\mathrm{b}}\end{array}$ & $\begin{array}{l}3 \\
2 \\
3 \\
2\end{array}$ & $\begin{array}{l}2 \\
1 \\
2 \\
1\end{array}$ & 16 \\
\hline 1 & $\begin{array}{l}1 \mathrm{a} \\
1 \mathrm{p} \\
2 \mathrm{a} \\
2 \mathrm{p}\end{array}$ & $\begin{array}{r}7 \\
7 \\
11 \\
9\end{array}$ & $\begin{array}{l}3 \\
4 \\
4 \\
7\end{array}$ & 52 \\
\hline
\end{tabular}

a In two adjacent quarters.

b In one quarter.
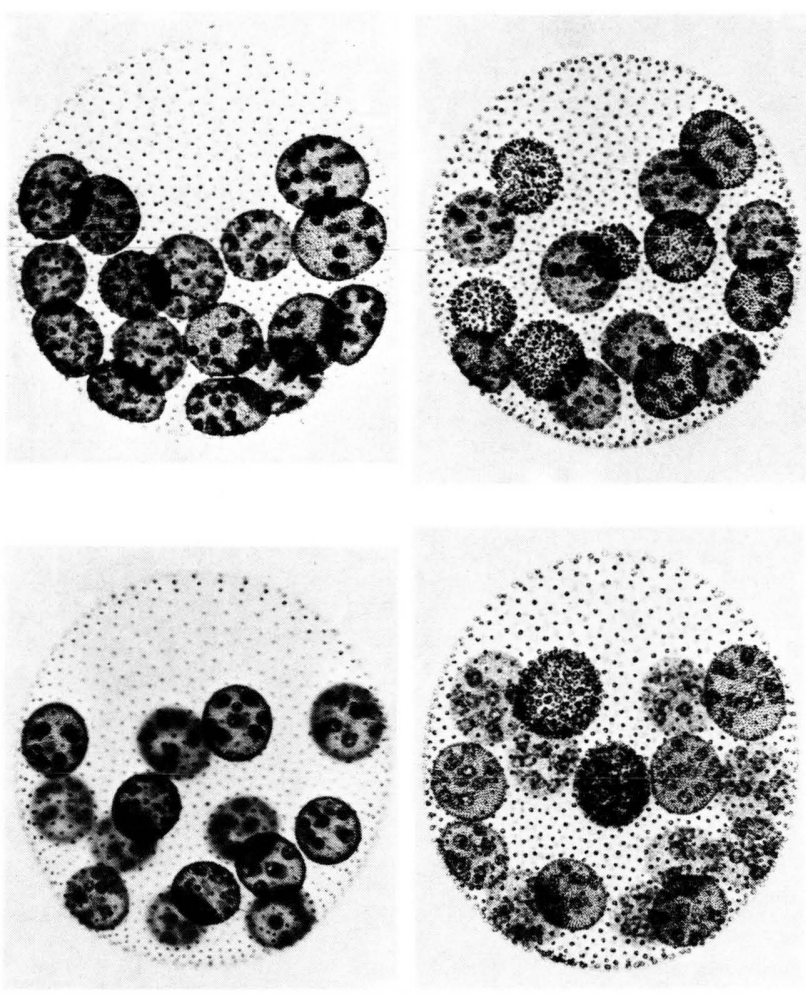

Fig. 2. Selected male and female spheroids containing multiple spontaneous induced offspring. Upper left: Female spheroids with 8 sexual daughters (containing ca. 32 eggs, each) in two adjacent quarters. Upper right: Male spheroid with 4 sexuals (containing a 1:1 ratio of androgonidia (=prospective sperm-packets) and somatic cells) in one quarter. Lower left: Female spheroid with 2 sexuals in the $1 a$ and $l p$ position. Lower right: Male spheroid with 2 sexuals in the $2 a$ and $2 p$ position. As demonstrated in Table I, all other possible patterns are also found in both strains. $(\times 50)$. taneous sexuals will be found. Single sexual daughter spheroids can only arise from an event later than the 16-cell stage. In each case the somatic cells are not visibly affected.

This explanation has important consequences for understanding sexual induction in Volvox:

(i) The basic event which establishes spontaneous sexuality is hereditary. Though we cannot exclude other possibilities, it is most likely that the event is on the DNA level, e.g. a mutation in a gene controlling sexual differentiation. Since chloroplast DNA is replicated prior to embryogenesis [10], nuclear DNA seems to be affected. We can thus consider the $\operatorname{sex}^{c}$ trait in male strains as a stable mutation, as was suggested in [4].

(ii) The sex mutation is an exquisite marker of cell lineages during embryogenesis. We now have direct proof for the validity of the correlation between gonidial initials at the 64-cell stage and the gonidia in the adult spheroid (Fig. 1) which was only derived so far from microscopical observations [9]. Even scanning electron microscopy pictures have been incorrectly interpreted [11] with respect to the origin of the gonidia. Our data, in particular the dual spontaneous sexual daughters, unequivocally show that two tiers, i.e. cells 1 and 2 of the 16-celled embryo, are gonidial stem cells.

(iii) The reported mode of entry into the sexual pathway is independent of inducer. No pheromone can be detected even in concentrated medium of asexual male cultures (until a $\operatorname{sex}^{c}$ male releases inducer). Inducer synthesis seems to be effectively repressed during the vegetative life cycle. 
(iv) If the mutation is expressed directly during embryogenesis, mixed spheroids would arise, composed of an asexual part with gonidia and a sexual one with either sperm-packets or eggs. No such chimeras have ever been observed. During inducerdependent induction, the irreversible decision, whether to enter the sexual or the asexual pathway, is made prior to the first cleavages of the gonidium [12]. The pattern of the sex mutants fits into this picture. Gonidial stem cells are unable to express the $s e x^{c}$ trait until they go through the critical phases before the next embryogenesis; then, the whole spheroid will become sexual. The time between the phase of decision and the first cleavage has to be very short, indeed; otherwise we would have found spheroids with 16 sexual offspring which will arise if the mutation occurs during this interval.

(v) From the relative frequency of the single and multiple $\operatorname{sex}^{c}$ mutants we may define the interval in which the mutation takes place. Assuming the probability of mutation as time-proportional we can deduce: During the first five divisions ( $1 \mathrm{~h}$ each) multiple sexuals are formed; a mutation from the 32 -cell stage to the next generation cycle $(43 \mathrm{~h})$ will lead to a single sexual; this relative frequency $\left(F_{\mathrm{r}}=\right.$ number of cells $\times$ time $)$ should be $22: 688$ or $1: 31$. This proportion is not observed (Table I). If we make the restriction that the $\operatorname{sex}^{c}$ mutation occurs only during cleavage and take into account that gonidial initials divide until the 512-cell stage [13], we calculate for $F_{\mathrm{r}} 22: 80$ or $1: 3.6$, a frequency which is close to that found $(1: 3.25)$.

[1] R. C. Starr, Arch. Protistenk. 111, 204-222 (1969).

[2] R. Gilles, C. Bittner, and L. Jaenicke, FEBS Letters 124, $57-61$ (1981).

[3] R. C. Starr, Devel. Biol. Suppl. 4, 59-100 (1970).

[4] R. C. Starr, Soc. bot. Fr., Mémoires 1972, 175-182.

[5] A. M. Callahan and R. J. Huskey, Devel. Biol. 80, 419-435 (1980).

[6] N. Kurn, M. Colb, and L. Shapiro, Devel. Biol. 66, 266-269 (1978).

[7] G. Kochert, Symp. Soc. Dev. Biol. 13, 55-90 (1975).

[8] R. C. Starr and L. Jaenicke, Proc. Natl. Acad. Sci. 71, 1050-1054 (1974).

[9] R. Gilles and L. Jaenicke, Z. Naturforsch. 37 c, $1023-1030$ (1982).

[10] A. W. Coleman, in Biochemistry and Physiology of Protozoa, 2nd edition, Vol. 1, 307-340 (M. Lewandowsky and S. H. Hutner, eds.), Academic Press, New York, London 1979.

Note added in proof:

We found a spontaneous pan mutant [5] in the $69-1 \mathrm{~b}$ strain. In the presence of inducer, the androgonidia of this
Hence we conclude that the $\operatorname{sex}^{c}$ mutation may be limited to cell division or is at least highly enhanced during that stage.

The primary event in sexual induction seems to be a high frequency mutation. The pheromone is a secondary synchronizing signal which enables a single sexual male to induce all Volvox carteri spheroids present in a volume of ca. $1 \mathrm{~m}^{3}$ [12]. Since a $\operatorname{sex}^{c}$ mutation is vital for regular sexual reproduction, it is very likely that a special mechanism had to be evolved to increase its frequency. In similar needs in other organisms, it is known that genome rearrangements are involved (references in [14]). An important example is the mating type switch in yeast [15] and the antigenic variability in Trypanosomes [16]. DNA rearrangements by movable transposons control gene expression during development of maize, sea urchin, Drosophila, and mice (review in [17]). So far we have no evidence for such rearrangements in Volvox, but normal base-pair exchanges cannot reasonably explain our results. Evaluation of the molecular basis of the $\operatorname{sex}^{c}$ mutation remains a challenging problem.

\section{Acknowledgements}

We thank Mrs. C. Gilles for expert and faithful technical assistance and Prof. R. C. Starr, Austin (Texas), for critical comments. Support by the Deutsche Forschungsgemeinschaft through SFB 74 and by the Fonds für Biologische Chemie is gratefully acknowledged.

[11] K. J. Green and D. L. Kirk, J. Cell Biol. 94, 741742 (1982).

[12] R. Gilles, C. Gilles, and L. Jaenicke, Z. Naturforsch. 39 c, 584-592 (1984).

[13] K. J. Green and D. L. Kirk, J. Cell Biol. 91, $743-755$ (1981).

[14] P. Starlinger, TIBS 9, 125-127 (1984).

[15] I. Herskowitz, L. Blair, D. Forbes, J. Hicks, Y. Kassir, P. Kushner, J. Rine, G. Jr. Sprague, and J. Strathern, in Molecular genetics of development, p. 79-118 (W. Loomis and T. Leighton, eds.), Academic Press London, New York 1980.

[16] K. Vickerman and J. D. Barry, in Immunology of Parasitic Infections, 2nd edition, p. 204-260 (S. Cohen and K. S. Warren, eds.), Blackwell, London 1982.

[17] U. Wintersberger, Naturwissenschaften 69, 107113 (1982).

mutant develop asexually; however, $\operatorname{sex}^{\mathrm{c}}$-mutants of this strain show only sexual spheroids in all following generations, even in the absence of inducer. 